\title{
Antitubercular Activity Increase in Labdane Diterpenes from Copaifera Oleoresin through Structural Modification
}

\author{
Aline N. Silva, ${ }^{a}$ Ana Carolina F. Soares, ${ }^{a}$ Mirela M. W. Cabral, ${ }^{a}$ Alex R. P. de Andrade, ${ }^{a}$ \\ Marilza B. M. da Silva, ${ }^{a}$ Carlos H. G. Martins, ${ }^{a}$ Rodrigo C. S. Veneziani, ${ }^{a}$ \\ Sérgio R. Ambrósio, ${ }^{a}$ Jairo K. Bastos ${ }^{b}$ and Vladimir C. G. Heleno $* a$ \\ ${ }^{a}$ Núcleo de Pesquisas em Ciências Exatas e Tecnológicas, Universidade de Franca, \\ 14404-600 Franca-SP, Brazil \\ ${ }^{b}$ Faculdade de Ciências Farmacêuticas de Ribeirão Preto, Universidade de São Paulo, \\ 14040-903 Ribeirão Preto-SP, Brazil
}

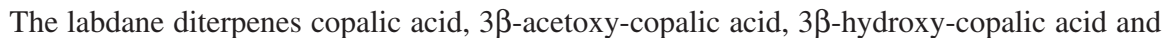
ent-agathic acid were isolated from Copaifera langsdorffii oleoresin. These four compounds were submitted to structural modifications by reduction with hydrogen/palladium, esterification with diazomethane, esterification with methanol/sulfuric acid and conversion into sodium salt, furnishing 15 compounds. All compounds were assayed in vitro against Mycobacterium tuberculosis (H37Rv, ATCC 27294). The four compounds displayed minimum inhibitory concentration (MIC) value of $125 \mu \mathrm{g} \mathrm{mL} \mathrm{m}^{-1}$, and were not considered active. A methylated derivative of compound $3 \beta$-hydroxy-copalic acid, and a sodium salt of copalic acid displayed MIC values of $25 \mu \mathrm{gL}^{-1}$ $(71.7 \mu \mathrm{M})$ and $6.25 \mu \mathrm{g} \mathrm{mL^{-1 }}(19.2 \mu \mathrm{M})$, respectively. The sodium salt of copalic acid stood out by displaying similar activity in comparison with streptomycin (MIC $6.25 \mu \mathrm{g} \mathrm{mL}^{-1}$ ) and a better activity compared to $\mu \mathrm{M}$ value of pyrazinamide (MIC $3.12 \mu \mathrm{g} \mathrm{mL} \mathrm{mL}^{-1} ; 25.34 \mu \mathrm{M}$ ). Therefore, the methylated derivative of compound $3 \beta$-hydroxy-copalic acid and the sodium salt of copalic acid should be considered for further studies.
\end{abstract}

Keywords: Copaifera oilresin, labdane diterpenes, structural modification, antitubercular activity, Mycobacterium tuberculosis

\section{Introduction}

Tuberculosis (TB) is a severe respiratory disease which causes deaths counted in millions every year. ${ }^{1,2}$ This contagious and airborne disease is caused by mycobacteria from the Mycobacterium tuberculosis complex and, ${ }^{1,2}$ since it is transmitted through air, it is certainly hard to control. ${ }^{3}$ Most active TB cases (75\%) are pulmonary, but one fourth of them affect other systems. ${ }^{3}$ The burden of TB involves estimated 9.6 million people infected and 1.5 million dead in 2014. Considering death from a single infectious agent, only human immunodeficiency virus (HIV) kills more than TB. ${ }^{2}$

It is evaluated by the World Health Organization $(\mathrm{WHO})^{2}$ that 480 thousand people developed multidrugresistant TB (MDR-TB) in 2014. Moreover, 190 thousand deaths from MDR-TB were estimated for the same year,

*e-mail: vladimir.heleno@unifran.edu.br leading to a ratio of mortality above $39 \%$. If we further consider that one third of the world population is infected with the tubercle bacillus, ${ }^{4}$ this gives us the dimension of this public health problem.

Although preventable, ${ }^{5} \mathrm{~TB}$ causes substantial morbidity, being one of the major causes of infection morbidity, ${ }^{6}$ that leads to human suffering and present a negative socioeconomic impact. ${ }^{7}$ Prevention is carried out mostly by the use of BCG (Bacille Calmette-Guérin) vaccine, the only one used to prevent TB. ${ }^{6}$ Nevertheless, it is not intensively used in several countries. ${ }^{6}$

Thus, it is clearly noted that TB is a serious world health problem that requires some serious measures. A promising way to do that is the search for novel therapeutics, mainly for drug resistant strains of TB. ${ }^{8}$ This can be provided by the search for new drugs to fight this disease, ${ }^{5}$ and the use of natural product is certainly an interesting option. ${ }^{9}$

The complex mixture which presents diverse composition, known as copaiba resin-oil, is widely used 
and applied in research works dealing with its reported biological activities. ${ }^{10-13}$ The trees which exude those resinoils are from the Copaifera genus, which includes several species..$^{14,15}$ Those medicinal plants are also commonly used in Brazilian folk medicine due to their pharmacological applications proved by popular use..$^{13,14}$ These oils may present diverse composition depending on their botanical source. This turns them an interesting source of natural products to be isolated and assayed against different pathological agents. ${ }^{16-18}$

Terpenoids are one of the largest classes of natural products, ${ }^{12}$ and some of them are widely used as starting materials in natural products synthesis. ${ }^{16}$ Some diterpenes displayed a remarkable antitubercular activity against M. tuberculosis, despite the fact that only a limited number of them were assayed against this pathogenic agent. ${ }^{4}$ Moreover, according to Rawat and Rawat, ${ }^{3}$ there are some cases where the semi-synthetic diterpenes were more active than the natural precursor and some of them with high activity against $M$. tuberculosis. ${ }^{3}$

As presented in most of the papers dealing with biological activities, one important goal is to reach a considerable number of structures to be assayed. Commonly, a slight difference in the compound structure leads to a considerable difference in biological activity, ${ }^{4}$ which makes structural modification a promising method to achieve more active and less toxic compounds.

Considering the potential of this class of compounds and our research interests in terpenoids, ${ }^{19-21}$ we decided to submit the previously isolated labdane diterpenes (1-4) to structural modifications searching for more active compounds against $M$. tuberculosis.

\section{Results and Discussion}

Isolation of natural diterpenes

The oleoresin sample was purchased from "Apis-Flora Comercial e Industrial", a Brazilian herbal company located in the city of Ribeirão Preto, state of São Paulo, under the register: lot 0790310, manufactured 09/2010. The natural diterpenes copalic acid (1), $3 \beta$-acetoxycopalic acid (2), 33-hydroxy-copalic acid (3) and ent-agathic acid (4) were isolated as described earlier by our research group. ${ }^{18}$ The isolated diterpenes $\mathbf{1}$ to $\mathbf{4}$ had their nuclear magnetic resonance (NMR) data compared to literature. ${ }^{22-24}$ Purity of the isolated compounds was estimated to be between $95-98 \%$ by NMR. All structures of natural and semi-synthetic diterpenes of this work are shown in Figure 1 and Scheme 1.

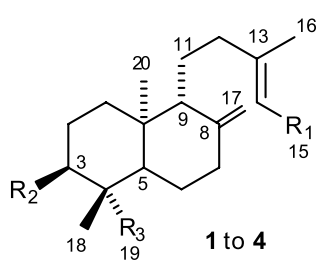
$\begin{array}{lll}\mathrm{R}_{1} & \mathrm{R}_{2} & \mathrm{R}_{3}\end{array}$
1. $\mathrm{COOH} ; \mathrm{H} ; \mathrm{CH}_{3}$
2. $\mathrm{COOH} ; \mathrm{AcO} ; \mathrm{CH}_{3}$
3. $\mathrm{COOH} ; \mathrm{OH} ; \mathrm{CH}_{3}$
4. $\mathrm{COOH} ; \mathrm{H} ; \mathrm{COOH}$

Figure 1. Structures of the natural diterpenes, precursors in this work.

\section{Synthetic structural modifications}

Structural modifications were performed by submitting the isolated compounds to four different protocols: reduction with hydrogen/palladium, esterification with diazomethane, esterification with methanol/sulfuric acid and conversion into sodium salt. Scheme 1 summarizes these transformations.

Catalytic hydrogenation of $\mathbf{1}$ to $\mathbf{4}$ produced compounds 5 to $\mathbf{8}$ in good yields. Both double bonds present in the starting compounds were reduced. The reduction of the terminal methylene (C8-C17) probably occur with high stereoselectivity: only the $\alpha$-methyl products may be obtained. This is what should be expected due to the presence of the bulky $\alpha$-substituent in $C 9$ and due to the relatively huge size of Pd particle, allowing the catalyst approach to occur only in the other surface of the double bond.

Treatment of $\mathbf{1}$ to $\mathbf{4}$ with diazomethane resulted in compounds 9, 10,13 and 14 . As expected, all carboxylic groups were converted into the corresponding methyl esters. However, in compound $\mathbf{3}$, it also took place a less usual conversion of the alcoholic $\mathrm{OH}$ group into the corresponding methyl ether, thus resulting in product 14.

The esterification with methanol/sulfuric acid is expected to produce essentially the same products obtained with diazomethane but, as it has been noted previously, ${ }^{21}$ some minor differences may occur resulting in additional derivatives. In fact, while starting compounds $\mathbf{1}$ and $\mathbf{2}$ led to the same products as the obtained by reacting with diazomethane, namely compounds $\mathbf{9}$ and $\mathbf{1 0}$, compounds $\mathbf{3}$ and $\mathbf{4}$ were converted into new derivatives $\mathbf{1 1}$ and $\mathbf{1 2}$, respectively. The alcoholic $\mathrm{OH}$ group of compound $\mathbf{3}$ was not transformed into methyl ether and, for compound $\mathbf{4}$, the neopentylic carboxyl group at $\mathrm{C} 4$ was not converted into methyl ester.

Compound 15 was obtained by the conversion of the acid diterpene $\mathbf{1}$ into a sodium salt. This was initially undertaken according to a procedure described in the literature. ${ }^{25}$ Nevertheless, it was verified that this method was not totally effective for our substrates. The products were either afforded in extremely low yielding, or could 
<smiles>[R7]C[C@H]1CC[C@@H]2CC(C)CC[C@H]2[C@@]2(C)CC[C@H]([R2])[C@]([R3])(C)[C@@H]12</smiles>

$$
\begin{array}{lll}
R_{1} & R_{2} & R_{3}
\end{array}
$$

5. $\mathrm{COOH} ; \mathrm{H} ; \mathrm{CH}_{3}$ 6. $\mathrm{COOH} ; \mathrm{AcO} ; \mathrm{CH}_{3}$ 7. $\mathrm{COOH} ; \mathrm{OH} ; \mathrm{CH}_{3}$ 8. $\mathrm{COOH} ; \mathrm{H} ; \mathrm{COOH}$

$$
\text { Yield: } 5 \text { - } 68 \quad 7-85
$$$$
\text { (\%) } \quad 6-77 \quad 8-97
$$
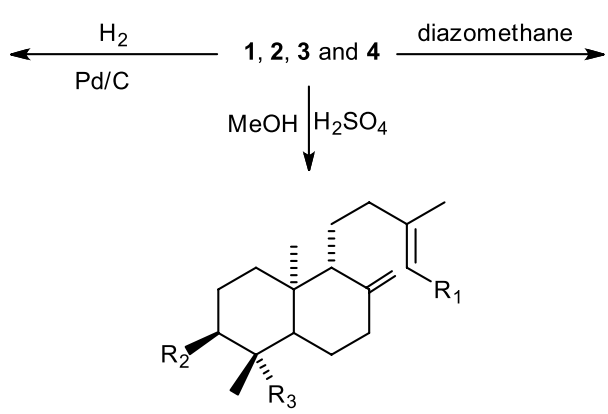

$\begin{array}{lll}\mathrm{R}_{1} & \mathrm{R}_{2} & \mathrm{R}_{3}\end{array}$

9. COOMe; $\mathrm{H} ; \mathrm{CH}_{3}$ 10. $\mathrm{COOMe} ; \mathrm{AcO} ; \mathrm{CH}_{3}$ 11. $\mathrm{COOMe} ; \mathrm{OH} ; \mathrm{CH}_{3}$ 12. $\mathrm{COOMe} ; \mathrm{H} ; \mathrm{COOH}$

Yield: $9-68 \quad 10-85$

(\%) $11-77 \quad 12-97$<smiles>[R]C=C1CCC2[C@@]1(C)CC[C@@H]1[C@@]2(C)CC[C@@H]([R2])[C@@]1([R3])C</smiles>

$\begin{array}{lll}\mathrm{R}_{1} & \mathrm{R}_{2} & \mathrm{R}_{3}\end{array}$

9. COOMe; $\mathrm{H} ; \mathrm{CH}_{3}$ 10. COOMe; $\mathrm{AcO} ; \mathrm{CH}_{3}$ 13. COOMe; $\mathrm{H} ; \mathrm{COOMe}^{2}$ 14. COOMe; $\mathrm{OMe} ; \mathrm{CH}_{3}$

Yield: $\begin{array}{lll}9 & -68 & 10-85\end{array}$ (\%) $\quad 13-77 \quad 14-97$

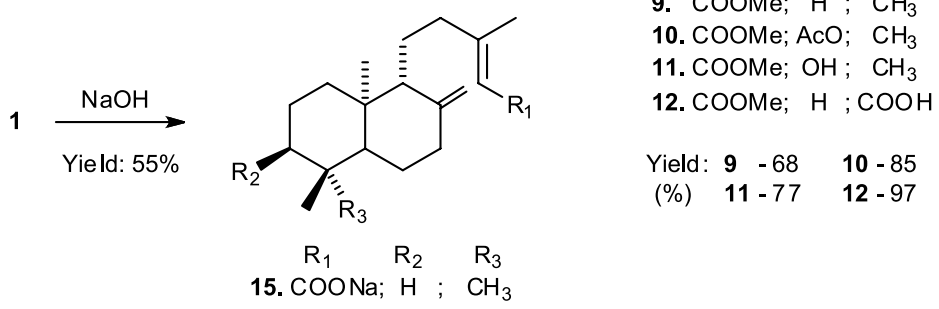

Scheme 1. Summary scheme of the structural modifications undertaken in this work.

not even be isolated from reaction mixtures. This made clear the need of a set of test reactions aiming to adapt conditions for better yields. Due to the availability of the natural compounds, the tests could be performed only with copalic acid (1), which is the major component of the oleoresin. The new procedure for $\mathbf{1}$ afforded product $\mathbf{1 5}$ in $55 \%$ yield.

Purities of the semi-synthetic compounds were estimated to be between 95 and $97 \%$ by NMR.

\section{Anti-tubercular activity}

The activities of all compounds were established by assaying them against the cell line Mycobacterium tuberculosis H37Rv, ATCC (American Type Culture Collection) 27294, as described in the Experimental section. Results are given as minimum inhibitory concentration (MIC) in $\mu \mathrm{g} \mathrm{mL}^{-1}$. Positive control for those experiments was the widely used anti-tubercular drug isoniazid. This drug is recommended and considered essential by the World Health Organization (WHO). ${ }^{26}$ Table 1 summarizes the obtained results and, moreover, presents the activity published in the literature of three other first line drugs in use for TB: ethambutol, pyrazinamide and streptomycin.

As seen on Table 1, none of the four isolated compounds presented activity against $M$. tuberculosis. They were all considered inactive, presenting MIC of $125 \mu \mathrm{g} \mathrm{mL}^{-1}$. This makes the structural modifications a search for active compounds.
Initially, the results obtained for the hydrogenation derivatives, compounds $\mathbf{5}$ to $\mathbf{8}$, will be considered. Despite the fact that compounds $\mathbf{6}$ and $\mathbf{7}$ showed the same activity as the natural compounds (inactive), compound $\mathbf{8}$ became

Table 1. Antitubercular activity results for all compounds and first line

\begin{tabular}{|c|c|c|c|}
\hline Compound & Precursor & $\mathrm{MIC} /\left(\mu \mathrm{g} \mathrm{mL}^{-1}\right)$ & $\mathrm{MIC} / \mu \mathrm{M}^{\mathrm{b}}$ \\
\hline 1 & - & 125 & 410.6 \\
\hline 2 & - & 125 & 344.8 \\
\hline 3 & - & 125 & 390.1 \\
\hline 4 & - & 125 & 373.8 \\
\hline 5 & 1 & 62.5 & 202.6 \\
\hline 6 & 2 & 125 & 341.0 \\
\hline 7 & 3 & 125 & 385.2 \\
\hline 8 & 4 & 250 & 738.6 \\
\hline 9 & 1 & 125 & 392.5 \\
\hline 10 & 2 & 125 & 332.0 \\
\hline 11 & 3 & 125 & 373.7 \\
\hline 12 & 4 & 125 & 358.7 \\
\hline 13 & 4 & 125 & 344.8 \\
\hline 14 & 3 & 25 & 71.7 \\
\hline 15 & 1 & 6.25 & 19.2 \\
\hline Ethambutol $^{27 \text { a }}$ & - & 1.64 & 7.22 \\
\hline Pyrazinamide ${ }^{28}$ & - & 3.12 & 25.34 \\
\hline Streptomycin ${ }^{28}$ & - & 6.25 & 10.75 \\
\hline Isoniazid & - & 0.06 & 0.44 \\
\hline
\end{tabular}
drugs 
even less effective and compound $\mathbf{5}$ became more active, showing that some slight difference in structure is capable to change activity. The activity displayed by compound $\mathbf{5}$ can be considered a moderate activity. First line drugs for $\mathrm{TB}$ are, at least, ten times more active.

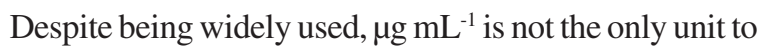
express MIC values. The concentration in $\mu \mathrm{M}$ (micromolar) is also an important parameter, or even a better one, as it takes into account the molar quantity of the active substance. If a comparison of the $\mu \mathrm{M}$ values is undertaken, compound $\mathbf{5}$ becomes relatively more active. The first line anti-tubercular drug pyrazinamide presents, in this new comparison, only eight fold the activity of the modified diterpene.

In all cases of hydrogenation, the only improvement of activity achieved was due to the hydrogenated product compound $\mathbf{5}$, which bears only one functional group, as seen on Scheme 1. On the other hand, in all other cases, there are two functional groups in each molecule, as also seen on Scheme 1 for compounds $\mathbf{6}$ to $\mathbf{8}$. Therefore, despite the reduction of the double bonds in all cases, it seems that the presence of two functional groups in the molecule hampers the increase of activity. If both functional groups are carboxylic acid, as seen in compound $\mathbf{8}$, the activity becomes even worse with the hydrogenation.

The methyl esters prepared from the natural compounds by reaction with diazomethane or by the methanol-sulfuric acid condition were also assayed against $M$. tuberculosis. Due to the similarity of the functional groups present in the derivatives 9-14, their biological activity results will be discussed as a single group.

Five from six derivatives obtained, named compounds 9 to $\mathbf{1 3}$, displayed the same low activity as the natural compounds, thus being considered inactive. On the other hand, compound $\mathbf{1 4}$ reached an activity that could be considered significant, displaying a MIC of $25 \mu \mathrm{g} \mathrm{mL}$. The activity of streptomycin, one of the first line drugs, is only four times more active than this. Nevertheless, the comparison of $\mu \mathrm{M}$ activity value for this compound with the value for pyrazinamide, shows that the commercial drug is less than three times more active than compound $\mathbf{1 4}$. Thus, a considerable activity was reached with this compound and it should be further investigated.

Comparing structures, one can roughly say that methyl esters cannot display better activities than the carboxylic acids against $M$. tuberculosis in those structures. Perhaps it can be further concluded, in a comparison of compounds 1-4 with compounds 9-13, that it makes no difference to have either methyl ester or carboxylic acid for this kind of activity. Nevertheless, compound $\mathbf{1 4}$ shows that a methoxyl group in position 3 can be crucial to express a much better activity. Neither hydroxyl nor acetoxyl groups in position 3 enhanced the activity, regardless the presence of another functional group in the molecule.

Finally, the evaluation of our sodium salt derivative (15) led to the most promising result in this work. Compound $\mathbf{1 5}$ reached a MIC value of $6.25 \mu \mathrm{g} \mathrm{mL}{ }^{-1}$, which is similar to streptomycin. Moreover, this derivative was more active (1.32 times) than pyrazinamide when considering $\mu \mathrm{M}$ values.

This gives rise to some future considerations in the search for active compounds against M. tuberculosis, especially among diterpenes. The activity of the salt indicates a possibility of water soluble compounds to be interesting for this kind of activity. Probably, the increased solubility of this compound allows this diterpene skeleton to reach some regions in the mycobacterial structure that is not achieved by the other less soluble derivatives, leading to this expressive activity.

Actually, only two kinds of structural feature showed to be relevant to anti-tubercular activity for this type of skeleton in this work: the presence of a methoxyl group in position 3; and a sodium salt prepared from the carboxylic acid, yielding a considerably more soluble structure. This can give rise for future works in the search for anti-tubercular agents.

\section{Conclusions}

The search for active compounds against $M$. tuberculosis, starting from natural labdane diterpenes, was successful. Simple structural modifications led to eleven derivatives, three of them were more active than the natural products. The best derivative displayed an activity comparable to two of the first line drugs for TB treatment. Due to the relevance of the results here presented, the natural diterpenes can be considered as promising for further investigations of the antitubercular activity, both as potential natural source or as prototypes for new active compounds.

\section{Experimental}

\section{Isolation of compounds}

The four natural diterpenes (1-4) were isolated from a sample of Copaifera langsdorffii oleoresin as described previously by our research group. ${ }^{18} \mathrm{~A}$ sample of $20.0 \mathrm{~g}$ of the oilresin furnishes $450.0 \mathrm{mg}$ of $\mathbf{1}, 230.0 \mathrm{mg}$ of $\mathbf{2}$, $130.0 \mathrm{mg}$ of $\mathbf{3}$ and $150.0 \mathrm{mg}$ of $\mathbf{4}$. The oleoresin was purchased from Apis Flora Company in Ribeirão Preto-SP, Brazil, lot 0790310. 


\section{General methods for compounds analysis}

NMR spectra were recorded on a Bruker Avance DRX 400 spectrometer $\left(400 \mathrm{MHz}\right.$ for ${ }^{1} \mathrm{H}$ and $100 \mathrm{MHz}$ for ${ }^{13} \mathrm{C}$ ). Samples were dissolved in $\mathrm{CDCl}_{3}$ or methanol- $d_{4}$, always in the concentration range from 8 to $16 \mathrm{mg} \mathrm{mL}^{-1}$. All samples were analyzed at $298 \mathrm{~K}$ and TMS (tetramethylsilane) was used as internal reference.

\section{Spectral identification of obtained compounds}

The natural compounds were fully identified by NMR spectral data, mainly by comparison to previously obtained data. ${ }^{18}$ The characterization of obtained compounds was easily undertaken with comparison of both ${ }^{1} \mathrm{H}$ NMR data, product and starting material. For the hydrogenation products, all signals are practically the same, except initially for the ones peculiarly related to olefinic hydrogens, which were all absent, confirming the hydrogenation of both double bonds in all cases. An extra signal for a methyl group was always noted in the products spectra, together with a shielding effect of the $\mathrm{CH}_{3}$ in position 16 , endorsing the structures of compounds 5-8. For the other derivatives, the structural determination was even easier, where the only difference is the presence of methoxyl groups' signals. Once the carboxylic group's hydrogen was not observed for any starting compound, the new signals were easily observed and led surely to the determination of the chemical structures of compounds 9-14.

The last structural confirmation needed was for compound 15. The extreme similarity between this product and its precursor (compound 1) could lead to the most difficult clarification. Instead of that, the structural confirmation was very clear. Most of the signals are exactly the same in compound $\mathbf{1 5}$, compared to the same signals in compound $\mathbf{1}$. The only difference, noted in the ${ }^{1} \mathrm{H}$ NMR spectrum, was the chemical shift of signals from $\mathrm{H}-12$ ( $\delta 2.00$ for $\mathbf{1 5}$ and 2.13 for $\mathbf{1})$ and $\mathrm{CH}_{3}-16(\delta 2.16$ for $\mathbf{1 5}$ and 2.28 for $\mathbf{1})$. These results are expected, because the carboxylic group induces a greater deshielding than the sodium carboxylate group. Moreover, the obtained product was not soluble in chloroform like compound $\mathbf{1}$. Deuterated methanol was needed for NMR analysis of the compound $\mathbf{1 5}$, corroborating its chemical structure, as previously described. ${ }^{29}$

\section{Structural modification experiments}

All experiments are described only once for all compounds, because the natural diterpene 1-4, used as starting materials, were submitted to quite similar procedures. In all cases, chromatographic methods, mainly open classic column chromatography, were applied to purify the obtained derivatives.

\section{Hydrogenation}

The natural diterpene $(0.05 \mathrm{~g})$ was initially dissolved in $20 \mathrm{~mL}$ of absolute ethanol and then, a catalytic portion of $\mathrm{Pd} / \mathrm{C}$ was added. The reactional mixture was placed in a pressure vessel and kept under stirring in a hydrogen atmosphere of $2 \mathrm{~atm}$, at room temperature, for two hours. After this, the mixture was filtered in Celite ${ }^{\odot}$ and the solvent was removed under reduced pressure. The products were all obtained as light yellow oils.

\section{Esterification with diazomethane}

In a round bottom $125 \mathrm{~mL}$ flask, $2.4 \mathrm{~g}$ of diazogen ( $N$-methyl- $N$-nitroso- $p$-toluenesulfonamide) were dissolved in anhydrous ethylic ether. The flask was cooled to $0{ }^{\circ} \mathrm{C}$ and a solution of $0.4 \mathrm{~g}$ of $\mathrm{KOH}$ in $10 \mathrm{~mL}$ of anhydrous ethylic ether was added dropwise to the mixture. After the addition, a distilling system was prepared with this flask and it was heated to $100{ }^{\circ} \mathrm{C}$. Produced diazomethane was distilled and collected in an Erlenmeyer placed in an ice bath $\left(0^{\circ} \mathrm{C}\right)$ as a solution in anhydrous ethylic ether. Immediately after its preparation, the diazomethane solution was added to the solution containing the acid diterpene, $50 \mathrm{mg}$ in $10 \mathrm{~mL}$ of ethyl ether, under stirring, until the gas $\left(\mathrm{N}_{2}\right)$ formation was ceased. The reaction mixture had the solvent removed under reduced pressure. All products were obtained as light yellow oils.

\section{Esterification with methanol}

In a round bottom $15 \mathrm{~mL}$ flask, a solution of the diterpene $(0.05 \mathrm{~g})$ in methanol $(5 \mathrm{~mL})$ was prepared. Then, 4 drops of concentrated sulfuric acid were slowly added and the final mixture was kept under stirring at room temperature for $18 \mathrm{~h}$. The reaction mixture was poured into an extraction funnel containing $40 \mathrm{~mL}$ of water. The final mixture was extracted with 3 portions ( $20 \mathrm{~mL}$ each) of ethyl acetate. The organic layer was dried under $\mathrm{MgSO}_{4}$ and the solvent was removed under reduced pressure.

\section{Sodium salt formation}

In a $25 \mathrm{~mL}$ Erlenmeyer flask, $0.05 \mathrm{~g}$ of copalic acid (1) was dissolved in $5 \mathrm{~mL}$ of $n$-hexane. To this mixture, $2.5 \mathrm{~mL}$ of a $\mathrm{NaOH} 0.5 \mathrm{M}$ solution was added and the final mixture was allowed to stir vigorously at room temperature for 3 minutes. After, the mixture was filtered in a cold Büchner funnel and the retained solid was washed once with cold methanol and once with cold water. The residue was left to dry under $50{ }^{\circ} \mathrm{C}$ in filter paper, from which the product, as a white solid, was then collected. 


\section{Antitubercular potential assays}

The obtained compounds were assayed against M. tuberculosis in LAPEMA (Research Laboratory of Applied Microbiology), UNIFRAN, under the responsibility of Prof Dr Carlos Henrique Gomes Martins, developer for the tests. The activity was determined by the minimum inhibitory concentration (MIC). Those MIC values were determined in triplicate, using the microdilution technique on a REMA (resazurin microtiter assay), adapted from a procedure reported in the literature. ${ }^{30}$

One milligram of each compound was dissolved in $125 \mu \mathrm{L}$ of dimethyl sulfoxide (DMSO) and $1875 \mu \mathrm{L}$ of Mueller Hinton broth was added. The final concentration of DMSO did not exceed $5 \%$, and the percentage of this solution was used as negative control. The $24 \mathrm{~h}$ cultures of microorganisms were transferred to tubes containing $10 \mathrm{~mL}$ of sterile saline solution. The suspension was standardized by comparing it with the McFarland tube $0.5(0.1 \mathrm{~mL}$ of a $1 \%$ solution of $\mathrm{BaCl}_{2}$ in $9.9 \mathrm{~mL}$ of a $1 \% \mathrm{H}_{2} \mathrm{SO}_{4}$ ). Then, serial dilutions in saline and finally in Mueller Hinton were performed to provide an inoculum of $5 \times 10^{5} \mathrm{CFU} \mathrm{mL}^{-1}$ (colony forming unit $\mathrm{mL}^{-1}$ ).

In the sterilized 96 wells microplates, a total of $100 \mu \mathrm{L}$ Mueller Hinton was added, with suspensions of microorganisms and the solutions of the compounds to be evaluated. All compounds were evaluated at different concentrations, allowing one to determine the concentration that was required to inhibit the growth of the evaluated microorganism. In one hole of each plate there was prepared the control culture, which must provide bacterial growth due to the absence of antimicrobial agents. Another hole was used for sterility control of the medium and Mueller Hinton, and another one for solvent control (DMSO) used to solubilize the tested samples. As a positive control, it was used isoniazid.

The plates were incubated at $37{ }^{\circ} \mathrm{C}$ for $24 \mathrm{~h}$. Subsequently, to each well, it was added $30 \mu \mathrm{L}$ of $0.02 \%$ aqueous solution of resazurin. After waiting for $18 \mathrm{~h}$, the presence of blue coloration (coloring resazurin solution) was interpreted as lack of bacterial growth and pink color indicated the presence of viable microorganisms.

\section{Acknowledgments}

The authors are grateful to CAPES, CNPq and FAPESP for funding. This work was mainly financially supported by State of São Paulo Research Foundation (FAPESP), grants No. 2009/09491-1 and 2011/13630-7.

\section{References}

1. Silva, M. L.A.; Martins, C. H. G.; Lucarini, R.; Sato, D. N.; Pavan, F. R.; Freitas, N. H. A.; Andrade, L. N.; Pereira, A. C.; Bianco, T. N. C.; Vinholis, A. H. C.; Cunha, W. R.; Bastos, J. K.; Silva, R.; Silva Filho, A. A.; Z. Naturforsch., B: J. Chem. Sci. 2009, 64c, 779.

2. World Health Organization (WHO); 2015 Global Tuberculosis Report. Available at: http://apps.who.int/iris/ bitstream/10665/191102/1/9789241565059_eng.pdf?ua=1, accessed in September 2016.

3. Rawat, B.; Rawat, D. S.; Med. Res. Rev. 2013, 33, 693.

4. Cantrell, C. L.; Franzblau, S. G.; Fischer, N. H.; Planta Med. 2001, 67, 685.

5. Webster, D.; Lee, T. D. G.; Moore, J.; Manning, T.; Kunimoto, D.; LeBlanc, D.; Johnson, J. A.; Gray, C. A.; Can. J. Microbiol. 2010, 56, 487.

6. Zwerling, A.; Behr, M. A.; Verma, A.; Brewer, T. F.; Menzies, D.; Pai, M.; PLoS Medicine 2011, 8, 1 .

7. Stavrakov, G.; Valcheva, V.; Philipova, I.; Doytchinova, I.; Eur. J. Med. Chem. 2013, 70, 372.

8. Kalalbandi, V. K. A.; Seetharamappa, J.; Katrahalli, U.; Bhat, K. G.; Eur. J. Med. Chem. 2014, 79, 194.

9. Cragg, G. M.; Grothaus, P. G.; Newman, D. J.; J. Nat. Prod. 2014, 77, 703.

10. Alencar, E. N.; Xavier, F. H.; Morais, A. R. V.; Dantas, T. R. F.; Dantas-Santos, N.; Verissimo, L. M.; Rehder, V. L. G.; Chaves, G. M.; Oliveira, A. G.; Egito, E. S. T.; J. Nanosci. Nanotechnol. 2015, 15,880 .

11. Dias, D. S.; Fontes, L. B. A.; Crotti, A. E. M.; Aarestrup, B. J. V.; Aarestrup, F. M.; da Silva, A. A.; Correa, J. O. A.; Molecules 2014, 19, 12814.

12. Zimmermam-Franco, D. C.; Bolutari, E. B.; Polonini, H. C.; do Carmo, A. M. R.; Chaves, M. D. G. A. M.; Raposo, N. R. B.; Molecules 2013, 18, 12561.

13. Veiga Jr, V. F.; Rosas, E. C.; Carvalho, M. V.; Henriques, M. G.; Pinto, A. C.; J. Ethnopharmacol. 2007, 112, 248.

14. Veiga Jr., V. F.; Pinto, A. C.; Quím. Nova 2002, 25, 273.

15. Lima Neto, J. S.; Gramosa N. V.; Silveira E. R.; Quim. Nova 2008, 31, 1078

16. Geris, R.; Silva, I. G.; Silva, H. H. G.; Barison, A.; RodriguesFilho, E.; Ferreira, A. G.; Rev. Inst. Med. Trop. Sao Paulo 2008, $50,25$.

17. Santos, A. O.; Izumi, E.; Ueda-Nakamura, T.; Dias-Filho, B. P.; Veiga Jr., V. F.; Nakamura, C. V.; Mem. Inst. Oswaldo Cruz 2013, 108, 59.

18. Souza, A. B.; Martins, C. H. G.; Souza, M. G. M.; Furtado, N. A. J. C.; Heleno, V. C. G.; Sousa, J. P. B.; Rocha, E. M. P.; Bastos, J. K.; Cunha, W. R.; Veneziani, R. C. S.; Ambrósio, S. R.; Phytother. Res. 2011, 25, 215.

19. Heleno, V. C. G.; Crotti, A. E. M.; Constantino, M. G.; Lopes, N. P.; Lopes, J. L. C.; Magn. Reson. Chem. 2004, 42, 364. 
20. Sass, D. C.; Heleno, V. C. G.; Morais, G. O.; Lopes, J. L. C.; Lopes, N. P.; Constantino, M. G.; Org. Biomol. Chem. 2011, 9, 6148 .

21. Andrade, B. B.; Moreira, M. R.; Ambrósio, S. R.; Furtado, N. A. J. C.; Cunha, W. R.; Heleno, V. C. G.; Silva, A. N.; Simão, M. R.; Rocha, E. M. P.; Martins, C. H. G.; Veeziani, R. C. S.; Nat. Prod. Commun. 2011, 6, 777.

22. Ohsaki, A.; Yan, L. T.; Ito, S.; Edatsugi, H.; Iwata, D.; Komoda, Y.; Bioorg. Med. Chem. 1994, 4, 2889.

23. Braun, S.; Breitenbach, H.; Tetrahedron 1977, 33, 145.

24. Zdero, C.; Bohlmann, F.; King, R. M.; Phytochemistry 1991 , 30, 2991.

25. Daló, N. L.; Sosa-Sequera, M. C.; Usubillaga, A.; Invest. Clin. 2007, 48, 349.

26. World Health Organization (WHO); Treatment of Tuberculosis Guidelines. Available at: http://apps.who. int/iris/bitstream/10665/44165/1/9789241547833_eng. pdf?ua=1\&locale=ru\&ua=1, accessed in September 2016.
27. Stavrakov, G.; Valcheva, V.; Philipova, I.; Doytchinova, I.; Eur. J. Med. Chem. 2013, 70, 372.

28. Kalalbandi, V. K. A.; Seetharamappa, J.; Katrahalli, U.; Bhat, K. G.; Eur. J. Med. Chem. 2014, 79, 194.

29. Porto, T. S.; Rangel, R.; Furtado, N. A. J. C.; Carvalho, T. C.; Martins, C. H. G.; Veneziani, R. C. S.; Da Costa, F. B.; Vinholis, A. H. C.; Cunha, W. R.; Heleno, V. C. G.; Ambrósio, S. R.; Molecules 2009, 14, 191.

30. Palomino, J. C.; Martin, A.; Camacho, M.; Guerra, H.; Swings, J.; Portaels, F.; Antimicrob. Agents Chemother. 2002, 46, 2720.

Submitted: July 25, 2016

Published online: September 30, 2016

FAPESP has sponsored the publication of this article. 